\title{
Organ-Specific Monitoring of Solitary Kidney after Living Donation by Using Markers of Glomerular Filtration Rate and Urinary Proteins
}

\author{
Gerit Theil Karl Weigand Kersten Fischer Joanna Bialek Paolo Fornara \\ Medical Faculty of Martin Luther University Halle-Wittenberg, University Clinic and Outpatient Clinic for Urology, \\ Halle/Saale, Germany
}

\section{Keywords \\ Living donation - Solitary kidney - Urinary protein · \\ Glomerular injury · Tubular function}

\begin{abstract}
Background: Effective follow-up after living kidney donation is important for maintaining the renal function of the donor. We investigated whether the estimated glomerular filtration rate (eGFR) and urinary protein and enzyme levels can provide important information regarding the state of the remaining kidney after donor nephrectomy. Methods: Seventy-five living donations were included (prospective/ retrospective) in the study. The following parameters were measured up to 1 year after donor nephrectomy: serum creatinine and cystatin C as markers of the GFR; the high-molecular-weight urinary proteins as markers of glomerular injury; and the low-molecular-weight urinary proteins and urinary enzymes as markers of tubular function. Results: One year after kidney donation, the creatinine and cystatin $C$ values were 1.38-fold increased than their initial values, while the eGFR was $32 \%$ lower. At that time, $38 \%$ of donors had a moderate or high risk of CKD progression. The biochemical urinary glomerular and tubular kidney markers examined
\end{abstract}

karger@karger.com www.karger.com/uin

Karger"

BOPEN ACCESS
(C) 2021 The Author(s)

Published by S. Karger AG, Basel

This is an Open Access article licensed under the Creative Commons Attribution-NonCommercial-4.0 International License (CC BY-NC) (http://www.karger.com/Services/OpenAccessLicense), applicable to the online version of the article only. Usage and distribution for commercial purposes requires written permission. showed different behaviors. After a transient increase, the glomerular proteins normalized. Conversely, the detection of low-molecular-weight urinary proteins and enzymes reflected mild tubular damage at the end of the study period. Conclusions: Our findings suggest that for the evaluation of mild tubular damage, low-molecular-weight marker proteins should be included in the urine diagnostic of a personalized living kidney donor follow-up.

(c) 2021 The Author(s).

Published by S. Karger AG, Basel

\section{Introduction}

In 2019, approximately one-fourth of all kidney transplants were made possible by a living donation [1]. The long-term safeguarding of donor health is a unique challenge, as donor nephrectomy (DN) transforms the donor from a healthy person into a patient. It is generally assumed that $\mathrm{DN}$ is safe $[2,3]$, but there are increasing doubts [4-8]. An important criterion for assessing patient safety is the risk of disease in the remaining single kidney or being required to undergo dialysis. Most studies are limited to the determination of the GFR and total urinary protein as kidney function parameters. After DN, 
organ-specific monitoring of the remaining kidney is rare [9-11]. Therefore, determination of a urinary protein profile is necessary $[12,13]$. High-molecular-weight proteins such as immunoglobulin $\mathrm{G}(\mathrm{IgG})$, albumin (Alb), and transferrin $(\mathrm{Tf})$ are detected in urine when the glomerular barrier is damaged, and low-molecular-weight proteins such as a1-microglobulin ( $\alpha 1 \mathrm{M}), \beta 2$-microglobulin $(\beta 2 \mathrm{M})$, retinol-binding protein $(\mathrm{RbP})$, and the urinary enzyme $\mathrm{N}$-acetyl- $\beta$-D-glucosaminidase (NAG) are found when tubular dysfunction or injury occurs. We investigated changes in the glomerular and tubular function of the remaining single kidney after DN. Are differences present among the kidney compartments? What is the postoperative course of these urinary biomarkers up to 1 year after surgery?

\section{Materials and Methods}

Seventy-five consecutive living donor nephrectomies were included in the study: 33 open (retrospective) and 42 hand-assisted laparoscopic (prospective) donor nephrectomies. Our project was approved by the Local Ethics Committee of the Martin Luther University Medical School Halle and written informed consent of the living donors obtained (Reference No. 2016-163). All living donors fulfilled the inclusion criteria according to the Amsterdam Forum [14]. The selection criteria for open and hand-assisted laparoscopic surgery were identical. Furthermore, the type of surgery was dependent on surgeon preference. The Ethical Guidelines of Human Medical Research of the Helsinki Declaration were followed. The following parameters were determined: serum creatinine and cystatin C levels (S-Crea and S-Cys C); total protein (UProt); the high-molecular-weight urinary proteins IgG, Alb, and $\mathrm{Tf}$; and the low-molecular-weight urinary proteins $\mathrm{RbP}, \alpha 1 \mathrm{M}$, and $\beta 2 \mathrm{M}$ and the urinary enzyme NAG. Urinary $\alpha 2$-macroglobulin was examined as a marker for the presence of postrenal blood. Urine and serum samples were obtained preoperatively and at 1 , 2 , 3, and 4 days; 1,3 , and 6 months; and 1 year after surgery (T0T8). To compensate for the concentration fluctuations of spot urine, the urinary markers were related to urinary creatinine. The urinary proteins and S-Cys C were determined nephelometrically (BN2; Siemens Healthcare Diagnostics GmbH, Eschborn, Germany), S-Crea was measured with the Jaffe method (SYNCHRON Lx-system; Beckmann Coulter GmbH, Krefeld, Germany), and NAG was determined colorimetrically using Cobas Mira (Roche, Mannheim, Germany). The eGFR was calculated using the cystatin $\mathrm{C}$ - and creatinine-based formula from the Chronic Kidney Disease Epidemiology Collaboration (CKD-EPI), CKD-EPI cys-crea $_{\text {eGFR }}$ [15]. The risk of CKD progression was determined according to the criteria defined by the NKF/KDOQI based on GFR categories $(G)$ and albuminuria (A) [15]. The descriptive statistics were calculated for all parameters. The course after $\mathrm{DN}$ is graphically displayed. For all measured proteins, the differences between the medians at baseline and the single measurement time points were determined by Wilcoxon matched-pair signed rank tests. The percentage of patients with abnormal urinary protein patterns at 1
Table 1. Patient characteristics

\begin{tabular}{ll}
\hline Variable & Result \\
\hline Age, years & $50.6(20-67)^{*}$ \\
BMI, kg/m² & $26.2(16.2-39.3)^{*}$ \\
Male/female, $n(\%)$ & $28(37.3) / 47(62.7)$ \\
$\begin{array}{l}\text { Open/hand-assisted laparoscopic surgery, } \\
\quad n(\%)\end{array}$ & $33(44) / 42(56)$ \\
\hline & \\
\hline
\end{tabular}

year after the live donation was determined. The patterns were classified as glomerular, tubular, or mixed proteinuria based on the available urinary protein values. $p$ values $<0.05$ were considered significant. All statistical analyses were performed using GraphPad Prism 6 (La Jolla, CA, USA) or SPSS 22 (IBM, Ehningen, Germany).

\section{Results}

The patient characteristics are shown in Table 1. The GFR markers increased to a maximum level (S-Crea and S-Cys C) or declined to a minimum level (CKD$\mathrm{EPI}_{\text {cys-creat }} \mathrm{eGFR}$ ) within 1 month. Thereafter, renal function stabilized. After 1 year, the S-Crea and S-Cys C values were approximately 1.38 times greater than and the eGFR was $32 \%$ less than the preoperative value (Table 2; Fig. 1). According to the criteria defined by the NKF/KDOQI, 1 year after DN, $34 \%$ of living donors showed a moderate (G1A2, G2A2, and G3aA1) and 4\% a high risk (G3aA2) of CKD progression [15] (G1, G2, and G3a correspond to GFR $\geq 90,60-90$, and $45-59 \mathrm{~mL} / \mathrm{min} / 1.73 \mathrm{~m}^{2}$; A1 and A2 correspond to albuminuria $<3$ and $3-30 \mathrm{~g} / \mathrm{mol}$ creatinine, respectively). We observed a transitory increase in all urinary proteins, reaching maximum values on the second or third day after surgery, but the increase was different for individual proteins. In contrast to the glomerular urinary proteins, the tubular proteins and the urinary enzyme NAG exhibited a greater increase (glomerular 1.833.97-fold and tubular 3.46-151-fold) and a slower decrease (Fig. 2). One year after DN, the mean and median values of all urinary proteins were greater than the preoperative values. The glomerular urinary proteins had declined into the reference range, and the tubular proteins $\alpha 1 \mathrm{M}$ and $\beta 2 \mathrm{M}$ remained higher. At all time points (T1T8), $\alpha 1 \mathrm{M}$ and NAG were significantly increased compared to baseline (Table 3). Urinary a2-macroglobulin could not be detected at any time point; therefore, the results were not influenced by postrenal blood. One year 
Table 2. GFR markers: median preoperative (T0) versus the median at 1 year after DN (T8)

\begin{tabular}{lccc}
\hline Parameter & T0 (range) & T8 (range) & Multiples T8/T0 \\
\hline S-Crea, $\mu \mathrm{mol} / \mathrm{L}$ & $73(45-107)$ & $101^{*}(62-149)$ & 1.38 \\
S-Cys C, $\mathrm{mg} / \mathrm{L}$ & $0.71(0.45-1.08)$ & $0.98^{*}(0.74-1.36)$ & 1.38 \\
eGFR, $\mathrm{mL} / \mathrm{min} / 1.73 \mathrm{~m}^{2}$ & $100(60-129)$ & $68^{*}(47-96)$ & 0.68 \\
\hline
\end{tabular}

DN, donor nephrectomy; eGFR, estimated glomerular filtration rate. ${ }^{*} p<0.0001$ T0 versus T8.

Fig. 1. S-Crea, S-Cys C, and eGFR after DN: multiples of the initial value versus measurement time points. d, day; mo, month; S-Crea, serum creatinine; S-Cys C, serum cystatin C; eGFR, glomerular filtration rate according to the CKD-EPIcys-creaeGFR formula; DN, donor nephrectomy.

Fig. 2. Urinary proteins and NAG after DN: multiples of the initial value versus measurement time points. IgG, immunoglobulin G/U-Crea; Alb, albumin/U-Crea; Tf, transferrin/U-Crea; $\alpha 1 \mathrm{M}, \quad \alpha 1$ microglobulin/U-Crea; RbP, retinol-binding protein/U-Crea; $\beta 2 \mathrm{M}, \quad \beta 2$-microglobulin/U-Crea; NAG, $N$-acetyl- $\beta$-Dglucosaminidase/U-Crea; U-Crea, urinary creatinine; DN, donor nephrectomy.
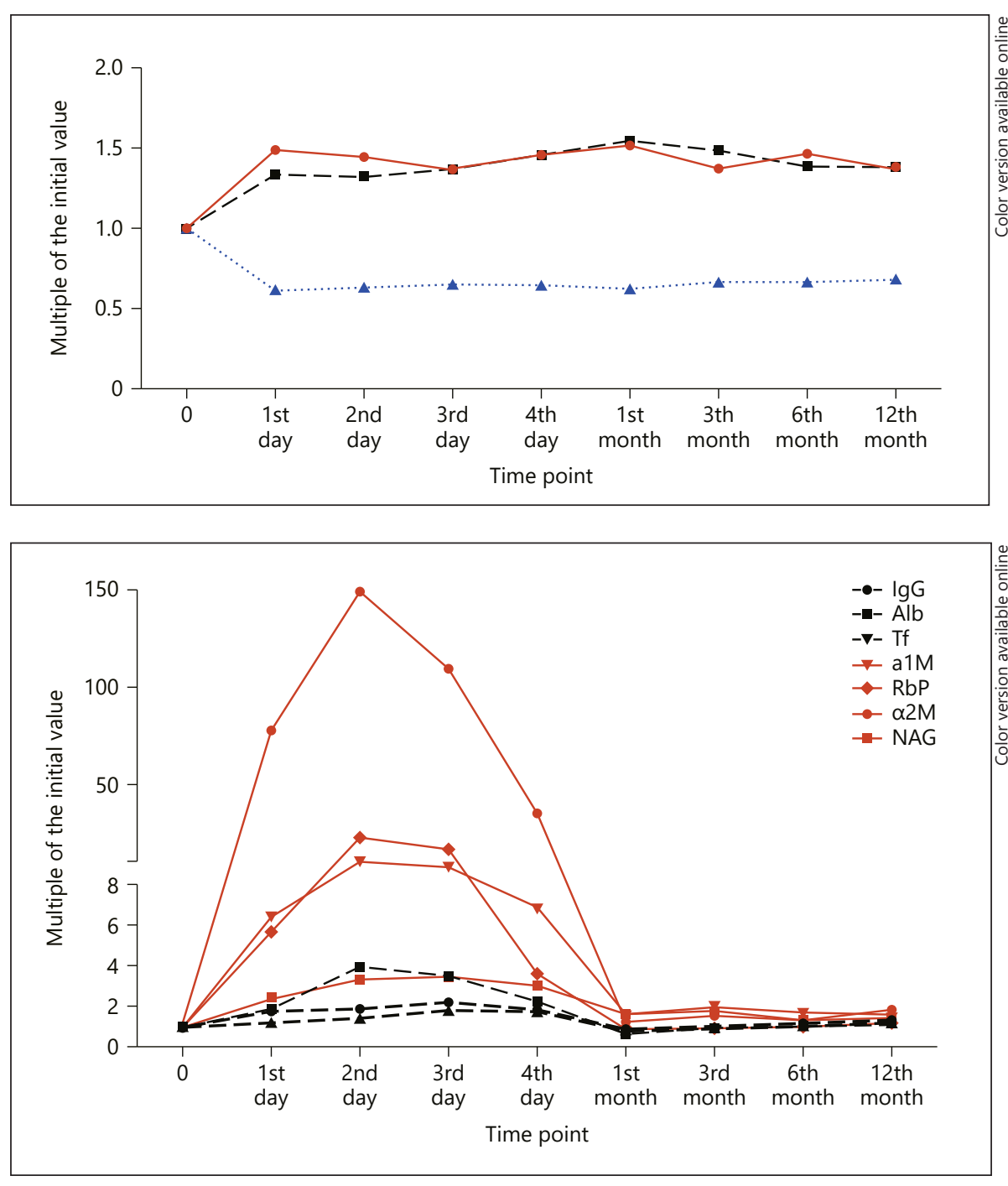

after nephrectomy, only $50 \%$ of the live donors had a normal urinary protein pattern. The high proportion of pure tubular urinary patterns was surprising (30\%; Fig. 3). Abnormal urinary protein patterns were not only found in patients at moderate or high risk of CKD progression but also in patients at low risk (37\%).

Organ-Specific Monitoring of Solitary Kidney

\section{Discussion}

\section{Patient Characteristics}

Parents and life partners donate a kidney most frequently, with the high proportion of women. Fact is that women are more altruistic than men and see kidney do- 
Table 3. Urinary proteins and NAG: median preoperative (T0) versus the median at 1 year after DN (T8)

\begin{tabular}{|c|c|c|c|}
\hline Parameter & T0 (range) & T8 (range) & Reference range \\
\hline U-Prot, mg/mL & $115(50-384)$ & $118(108-298)$ & 120 \\
\hline U-IgG/U-Crea, g/mol & $0.56(0.22-6.95)$ & $0.74(0.17-11.9)$ & $<1$ \\
\hline U-Alb/U-Crea, g/mol & $0.73(0.27-6.20)$ & $0.89(0.25-20.9)$ & $<2.3$ \\
\hline U-Tf/U-Crea, g/mol & $0.34(0.13-2.33)$ & $0.37(0.10-2.60)$ & $* *$ \\
\hline U-RbP/U-Crea, g/mol & $0.16(0.04-0.76)$ & $0.20(0.05-1.34)$ & $* *$ \\
\hline U- $\alpha 1 \mathrm{M} / \mathrm{U}-\mathrm{Crea}, \mathrm{g} / \mathrm{mol}$ & $1.05(0.28-3.59)$ & $1.71 *(0.35-8.96)$ & $<1.6$ \\
\hline $\mathrm{U}-\beta 2 \mathrm{M} / \mathrm{U}-\mathrm{Crea}, \mathrm{g} / \mathrm{mol}$ & $0.03(0.01-1.74)$ & $0.06(0.01-2.11)$ & $<0.03$ \\
\hline U-NAG/U-Crea, U/mmol & $0.28(0.01-0.94)$ & $0.41 *(0.19-1.70)$ & $* *$ \\
\hline
\end{tabular}

DN, donor nephrectomy; IgG, immunoglobulin G; Alb, albumin; Tf, transferrin; $\alpha 1 \mathrm{M}$, a1-microglobulin; $\mathrm{RbP}$, retinol-binding protein; $\beta 2 \mathrm{M}, \beta 2$-microglobulin; NAG, $\mathrm{N}$-acetyl- $\beta$-D-glucosaminidase. ${ }^{*} p<0.005$ T0 versus T8. ${ }^{* *}$ Reference range is not defined.

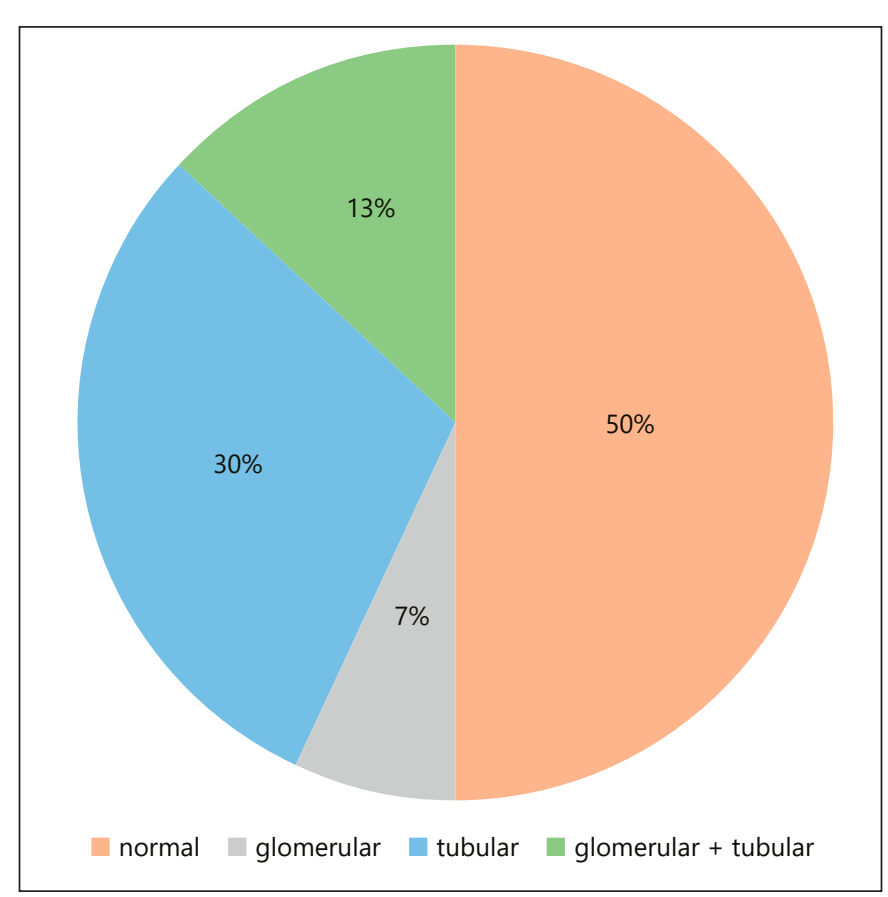

Fig. 3. Percentage distribution of urinary protein patterns at 1 year after living donation. Normal, no abnormalities; glomerular, at least 1 glomerular protein is increased; tubular, at least 1 tubular protein is increased; glomerular + tubular, at least 1 glomerular and 1 tubular protein are increased.

nation as a duty to help their suffering child or partner [16]. The type of surgery has no influence on the donor kidney function in our study population, which was confirmed in the analysis of similar patient collective in our clinic (data not shown). Such results were also demonstrated in other trials $[17,18]$. In the guideline originated form the Kidney Disease: Improving Global Outcomes
(KDIGO) Executive Committee in consultation with the Transplantation Society, the "mini-open," laparoscopy or hand-assisted laparoscopy by trained surgeons is suggested as the optimal approach to DN [19]. Additionally, in our investigation, we did not distinguish between left-sided and right-sided DN. The investigations of Weigand et al. [20] confirmed the correctness of our decision and summarized that also the right-sided $\mathrm{DN}$ is a safe procedure.

\section{Markers of the Glomerular Filtration Rate}

Markers of the GFR (S-Crea and S-Cys C) and the creatinine-based GFR are most frequently used for the assessment of renal function and for follow-up of living donors. Compared to S-Crea, S-Cys is more sensitive for detecting changes in renal function [21]. Due to the difficult method, the GFR is not generally measured, but formulas to calculate the eGFR, for example, based on SCrea or S-Cys C levels, are used. The most suitable formula for follow-up of living donors has been debated [22-24]. The deterioration of the eGFR that occurs shortly after kidney donation (by up to 50\%) and the subsequent stabilization of renal function approximately 1 month later conform to previously published data [25, 26]. Compensatory mechanisms in the remaining kidney are considered to account for the improvement of the eGFR over time [27]. One year after DN, renal function is reduced by approximately $30 \%$ of the preoperative value [28-30], which confirmed our results. At the end of the study period, more than a third of our living donors had a moderate to high risk of CKD progression, similar to reports by other authors [31-33]. However, Kishnan et al. [34] demonstrated no higher risk of development of CKD stage $4 / 5\left(\mathrm{eGFR}<30 \mathrm{~mL} / \mathrm{min} / 1.73 \mathrm{~m}^{3}\right)$ in $<10$-year fol- 
low-up after comparison of live donor datasets from the UK Transplant Registry with the cohort of healthy nondonors from the Health Improvement Network database. The authors emphasized that the British Transplantation guidelines recommend a lifelong follow-up of live donors. Therefore, it is possible that an early diagnosis and intervention of CKD minimizes the risk of end-stage renal disease [34].

\section{Urinary Proteins and Enzymuria}

Patients with a solitary kidney should be monitored regularly throughout their lives. Typically, blood pressure, renal function (eGFR), and proteinuria are measured. An increase in arterial hypertension and proteinuria in the long-term course after nephrectomy has been described [35]. The risk of a donor becoming subject to dialysis is controversial $[3,5]$. However, most studies evaluating renal function after living donation were limited to the determination of the eGFR, U-Prot, and sometimes urinary Alb levels. The results of different studies are very heterogeneous, which is partly due to differences in the size and composition of the study groups as well as the length of follow-up $[2,3]$. Both urinary U-Prot and Alb are significantly increased only during the long-term course ( $>10$ years) after DN [36]. Our study is the first to analyze the course of glomerular and tubular urinary proteins after DN over 1 year.

Consistent with our results, no significant increase in $\mathrm{U}$-Prot or Alb concentrations in the urine, compared to the preoperative values, was detected at 1 year after donation [37]. The observed significant short-term increase in urinary Alb in our study, with a maximum level on the second day after the surgery, was also described by other authors [11, 38]. Hoogendijk-van den Akker et al. [11] hypothesized that the short-term Alb elevation could be caused by glomerular permeability during surgery. No studies have examined the behavior of the high-molecular-weight glomerular urinary proteins IgG and $\mathrm{Tf}$ after $\mathrm{DN}$ [39]. In our study, similar to Alb, IgG and Tf levels were increased for a short time and then stabilized. The 2 -fold increase in the median, with a maximum value on the third day after surgery, was significantly lower than that of Alb (3.5-fold increase). A postrenal cause could be excluded. At the end of the year, the medians of all 3 glomerular urinary proteins were within the reference ranges.

Commonly used markers such as creatinine and UProt are not sufficiently sensitive for early detection of kidney damage, particularly injury of the proximal tubule. Markers indicating tubular injury before functional loss, such as low-molecular-weight urinary proteins or urinary enzymes, contribute little to the amount of total protein and are insufficient or not detectable by conventional quantitative or semiquantitative protein analytical methods [12]. If the proximal tubules are dysfunctional, the low-molecular-weight proteins are present in higher levels in the urine $[40,41]$. In addition to $\alpha 1 \mathrm{M}$ and $\beta 2 \mathrm{M}$, $\mathrm{RbP}$ is a sensitive marker of damage in the tubules [42]. Enzymes of tubular origin, such as NAG, a lysosomal high-molecular-mass enzyme, are released into the urine in response to lesions of tubule cells [43]. The amount of enzyme detectable in the urine correlates directly with the tubular disorder [41]. Our findings provide information on tubular kidney damage after DN. This damage is indicated by the extreme increase in tubular markers shortly after the operation ( $\beta 2 \mathrm{M} 150$-fold, RbP 23 -fold, $\alpha 1 \mathrm{M} 10$ fold, and NAG 3.5-fold) and by the fact that no normalization occurs within 1 year. Argiles et al. [9] reported adaptive changes in the remaining single kidney after $\mathrm{DN}$. The authors explained the significant increase in $\beta 2 \mathrm{M}$ and $\mathrm{RbP}$ excretion by changes in tubule function. Gluhovschi et al. [10] emphasized the importance of tubular lesions of the solitary kidney. In their review, they described the "solitary kidney" under different conditions, among other factors, after living donation. They recommend an extension of monitoring of patients with a solitary kidney, usually consisting of measurements of blood pressure, proteinuria, and eGFR, to the measurement of tubular injury markers. Hoogendijk-van den Akker et al. [11] investigated Alb and a1M after DN. As we also noted, they described the different behaviors of both urinary proteins; Alb was only increased in the short term, while a $1 \mathrm{M}$ slowly increased to a maximum level on the third day after surgery and remained elevated after 4-6 weeks. In a long-term follow-up study, Meier et al. [44] revealed a significant 6 times higher concentration of a1M 10 years after DN. These results confirmed our findings and indicate tubular dysfunction in the solitary kidney. The tubular markers we examined at 1 year after the surgery were significantly higher than the initial values and above the reference ranges. Similar observations are available for NAG. Elevated NAG values, compared to those of a healthy control group, have been described after DN [43].

Related to the results of Regeniter et al. [13], we also found abnormal urinary protein patterns in patients at low risk to CKD progression. The authors explained that kidney damage may already be present despite normal laboratory findings and before the eGFR is significantly reduced. To avoid overlooking a risk for disease, they rec- 
ommended a proteinuria analysis that includes both glomerular and tubular kidney markers, especially for highrisk patients [13]. Undoubtedly, this group includes individuals with a single kidney. The determination of the urinary marker proteins Alb (glomerular) and a1M (tubular) during follow-up supports the detection of possible kidney damage early. These results could help to prepare donors to optimize the postdonation outcomes like lifestyle modification for protection of the solitary kidney.

\section{Conclusion}

We investigated the influence of $\mathrm{DN}$ on the function and status of the remaining solitary kidney up to 1 year after surgery. At the end of the study period, more than a third of our living donors had a moderate to high risk at progression of CKD. The biochemical glomerular and tubular kidney markers examined showed different behaviors. After a transient increase, the glomerular proteins normalized. Conversely, the detection of low-molecularweight urinary proteins and enzymuria reflected mild tubular damage at 1 year after the DN. Our findings suggest that for the evaluation of mild tubular damage, low-molecular-weight marker proteins should be included in the urine diagnostic of a personalized living kidney donor follow-up. However, further studies are needed to confirm if urinary markers can improve the risk stratification of living kidney donors.

\section{Statement of Ethics}

Our project was approved by the Local Ethics Committee of the Martin Luther University Medical School Halle and written informed consent of the living donors obtained (Reference No. 2016163).

\section{Conflict of Interest Statement}

The authors have no conflicts of interest to declare.

\section{Funding Sources}

The authors have no funding to declare.

\section{Author Contributions}

The individual contribution of each coauthor is as follows: As the corresponding author, Gerit Theil took part in collecting and analyzing the data, drafting the article, and finally approving the study. Kersten Fischer, PhD, and Joanna Bialek, PhD, contributed in analysis and interpretation of data. Karl Weigand, MD, was involved in drafting the manuscript and final approval of the version to be published. Prof. MD Paolo Fornara contributed by drafting and approving the article and conception and design of the study and providing intellectual content of critical importance to the work described. All authors fulfill the criteria of ICMJE authorship, deserve credit, and can take responsibility for the work.

\section{References}

1 Eurotransplant, E.-S.C.O. Available from: https: //statistics.eurotransplant.org/index. php. 2020.

2 Garg AX, Muirhead N, Knoll G, Yang RC, Prasad GV, Thiessen-Philbrook H, et al. Proteinuria and reduced kidney function in living kidney donors: a systematic review, metaanalysis, and meta-regression. Kidney Int. 2006;70(10):1801-10.

3 Delanaye P, Weekers L, Dubois BE, Cavalier E, Detry O, Squifflet JP, et al. Outcome of the living kidney donor. Nephrol Dial Transplant. 2012;27(1):41-50.

4 Mjoen G, Hallan S, Hartmann A, Foss A, Midtvedt K, Oyen O, et al. Long-term risks for kidney donors. Kidney Int. 2014;86(1):162-7.

5 Muzaale AD, Massie AB, Wang MC, Montgomery RA, McBride MA, Wainright JL, et al. Risk of end-stage renal disease following live kidney donation. JAMA. 2014;311(6):57986.
6 Lam NN, Lentine KL, Levey AS, Kasiske BL, Garg AX. Long-term medical risks to the living kidney donor. Nat Rev Nephrol. 2015; 11(7):411-9.

7 Maggiore U, Budde K, Heemann U, Hilbrands L, Oberbauer R, Oniscu GC, et al. Long-term risks of kidney living donation: review and position paper by the ERA-EDTA DESCARTES working group. Nephrol Dial Transplant. 2017;32(2):216-23.

8 O'Keeffe LM, Ramond A, Oliver-Williams C, Willeit P, Paige E, Trotter P, et al. Mid- and long-term health risks in living kidney donors: a systematic review and meta-analysis. Ann Intern Med. 2018;168(4):276-84.

9 Argiles A, Mourad G, Basset N, Axelrud-Cavadore $\mathrm{C}$, Haiech J, Mion C, et al. Acute adaptative changes to unilateral nephrectomy in humans. Kidney Int. 1987;32(5):714-20.
10 Gluhovschi GH, Gadalean F, Gluhovschi C, Velciov S, Petrica L, Timar R, et al. Biomarkers in assessing tubular lesions of the solitary kidney. The solitary kidney in special conditions. Rom J Intern Med. 2013;51(3-4):13542.

11 Hoogendijk-van den Akker JM, Warlé MC, van Zuilen $\mathrm{AD}$, Kloke $\mathrm{HJ}$, Wever $\mathrm{KE}$, d'Ancona FC, et al. Urinary biomarkers after donor nephrectomy. Transpl Int. 2015;28(5): 544-52.

12 Hofmann WE, Edel HH, Guder WG, Ivandic M, Scherberich JE. Harnuntersuchungen zur differenzierten diagnostik einer proteinurie. Dtsch Arztebl Int. 2001;98.

13 Regeniter A, Freidank H, Dickenmann M, Boesken WH, Siede WH. Evaluation of proteinuria and GFR to diagnose and classify kidney disease: systematic review and proof of concept. Eur J Intern Med. 2009;20(6):55661. 
14 Delmonico F; Society Council of the Transplantation. A report of the amsterdam forum on the care of the live kidney donor: data and medical guidelines. Transplantation. 2005; 79(6 Suppl):S53-66.

15 Inker LA, Astor BC, Fox CH, Isakova T, Lash JP, Peralta CA, et al. KDOQI US commentary on the 2012 KDIGO clinical practice guideline for the evaluation and management of CKD. Am J Kidney Dis. 2014;63(5):713-35.

16 Biller-Andorno N. Gender imbalance in living organ donation. Med Health Care Philos. 2002;5(2):199-204.

17 Carrion DM, Gomez Rivas J, Aguilera Bazan A, Alonso YGS, De Castro Guerin C, AlvarezMaestro M, et al. Laparoscopic donor nephrectomy versus open donor nephrectomy: outcomes from a single transplant center. Arch Esp Urol. 2019;72(5):508-14.

18 Kok NF, Ijzermans JN, Alwayn IP. Re: laparoscopic versus open live donor nephrectomy in renal transplantation: a meta-analysis. Ann Surg. 2008;248(4):691-3. author reply 692-3.

19 Lentine KL, Kasiske BL, Levey AS, Adams PL, Alberú J, Bakr MA, et al. Summary of kidney disease: improving global outcomes (KDIGO) clinical practice guideline on the evaluation and care of living kidney donors. Transplantation. 2017;101(8):1783-92.

20 Weigand K, Kawan F, Schumann A, Mohammed N, Lindner F, Fornara P. [Right-sided or left-sided donor nephrectomy-is this really relevant?] Urologe A. 2020;59(1):32-9.

21 Bang JY, Kim SO, Kim SG, Song JG, Hwang GS. Cystatin-C is associated with partial recovery of kidney function and progression to chronic kidney disease in living kidney donors: observational study. Medicine. 2017; 96(5):e6037.

22 Issa N, Kukla A, Jackson S, Riad SM, Foster MC, Matas AJ, et al. Comparison of cystatin $\mathrm{C}$ and creatinine-based equations for GFR estimation after living kidney donation. Transplantation. 2014;98(8):871-7.

23 Tsuda A, Ishimura E, Uedono H, Yasumoto M, Ichii M, Nakatani S, et al. Comparison of the estimated glomerular filtration rate (eGFR) in diabetic patients, non-diabetic patients and living kidney donors. Kidney Blood Press Res. 2016;41(1):40-7.
24 Gozdowska J, Urbanowicz A, Sadowska A, Bieniasz M, Wszoła M, Kieszek R, et al. Glomerular filtration rate estimation in prospective living kidney donors: preliminary study. Transplant Proc. 2014;46(8):2592-7.

25 Choi KH, Yang SC, Joo DJ, Kim MS, Kim YS, Kim SI, et al. Clinical assessment of renal function stabilization after living donor nephrectomy. Transplant Proc. 2012;44(10): 2906-9.

26 Tomic A, Jevtic M, Novak M, Ignjatovic L, Zunic G, Stamenkovic D. Changes of glomerular filtration after nephrectomy in living donor. Int Surg. 2010;95(4):343-9.

27 Chen Z, Fang J, Li G, Zhang L, Xu L, Pan G, et al. Compensatory changes in the retained kidney after nephrectomy in a living related donor. Transplant Proc. 2012;44(10):2901-5.

28 Hew MN, Opondo D, Cordeiro ER, van Donselaar-van der Pant KA, Bemelman FJ, Idu $\mathrm{MM}$, et al. The 1-year decline in estimated glomerular filtration rate (eGFR) after radical nephrectomy in patients with renal masses and matched living kidney donors is the same. BJU Int. 2014;113(5b):E49-55.

29 Sansalone CV, Maione G, Aseni P, Rossetti O, Mangoni I, Soldano S, et al. Early and late residual renal function and surgical complications in living donors: a 15-year experience at a single institution. Transplant Proc. 2006; 38(4):994-5.

30 Song T, Rao Z, Qiu Y, Liu J, Huang Z, Wang $\mathrm{X}$, et al. Impact of remaining kidney volume to body weight ratio on renal function in living kidney donors. Kaohsiung J Med Sci. 2016;32(4):185-90.

31 Patel N, Mason P, Rushton S, Hudson A, Ploeg R, Friend P, et al. Renal function and cardiovascular outcomes after living donor nephrectomy in the UK: quality and safety revisited. BJU Int. 2013;112(2):E134-42.

32 Lenihan CR, Busque S, Derby G, Blouch K, Myers BD, Tan JC. Longitudinal study of living kidney donor glomerular dynamics after nephrectomy. J Clin Invest. 2015;125(3): $1311-8$.

33 Ibrahim HN, Foley RN, Reule SA, Spong R, Kukla A, Issa N, et al. Renal function profile in white kidney donors: the first 4 decades. J Am Soc Nephrol. 2016;27(9):2885-93.
34 Krishnan N, Mumford L, Lipkin G, Gill P, Fletcher S, Dasgupta I, et al. Comparison of medium-term outcomes of living kidney donors with longitudinal healthy control in the United Kingdom. Transplantation. 2020; 104(3):e65-74.

35 Fehrman-Ekholm I, Kvarnström N, Söfteland JM, Lennerling A, Rizell M, Odén A, et al. Post-nephrectomy development of renal function in living kidney donors: a cross-sectional retrospective study. Nephrol Dial Transplant. 2011;26(7):2377-81.

36 Li SS, Huang YM, Wang M, Shen J, Lin BJ, Sui $\mathrm{Y}$, et al. A meta-analysis of renal outcomes in living kidney donors. Medicine. 2016;95(24): e3847.

37 Kasiske BL, Anderson-Haag T, Ibrahim HN, Pesavento TE, Weir MR, Nogueira JM, et al. A prospective controlled study of kidney donors: baseline and 6-month follow-up. Am J Kidney Dis. 2013;62(3):577-86.

38 Yoon YE, Lee KS, Choi KH, Kim KH, Yang SC, Han WK. Prospective measurement of urinary microalbumin in living kidney donor nephrectomy: toward understanding the renal functional recovery period. J Urol. 2014; 192(4):1172-7.

39 Artz MA, Dooper PM, Meuleman EJ, van der Vliet JA, Wetzels JF. Time course of proteinuria after living-donor kidney transplantation. Transplantation. 2003;76(2):421-3.

40 Bang LE, Holm J, Svendsen TL. Retinol-binding protein and transferrin in urine. New markers of renal function in essential hypertension and white coat hypertension? Am J Hypertens. 1996;9(10 Pt 1):1024-8.

41 Adiyanti SS, Loho T. Acute kidney injury (AKI) biomarker. Acta Med Indones. 2012; 44(3):246-55.

42 Norden AG, Lapsley M, Unwin RJ. Urine retinol-binding protein 4: a functional biomarker of the proximal renal tubule. Adv Clin Chem. 2014;63:85-122.

43 Lisowska-Myjak B. Serum and urinary biomarkers of acute kidney injury. Blood Purif. 2010;29(4):357-65.

44 Meier M, Winterhoff J, Fricke L, Lehnert H, Nitschke M. Structural and functional adaptation of the remnant kidney after living kidney donation: long-term follow-up. Transplant Proc. 2017;49(9):1993-8. 